\title{
OPTIONS FOR MONITORING THE U.S.- RUSSIAN BILATERAL CUTOFF AGREEMENT ON SHUTDOWN OF PLUTONIUM PRODUCTION REACTORS
}

\author{
JONATHAN SANBORN \\ LESLIE G. FISHBONE \\ MING-SHIH LU \\ Brookhaven National Laboratory \\ WILLIAM STANBRO \\ Los Alamos National Laboratory \\ RICHARD LIBBY \\ Pacific Northwest Laboratory
}

July 1994

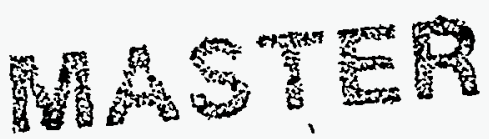

DISTRIBUTION OF THIS DOCUMENTT IS UNLIMITED BS|PIf 


\section{DISCLAIME]R}

This report was prepared as an account of work sponsored by an agency of the United States Government. Neither the United States Government nor any agency thereof, or any of their employees, makes any warranty, express or implied, or assumes any legal liability or responsibility for the accuracy, completeness, or usefulness of any information, apparatus, product, or process disclosed, or represents that its use would not infringe privately owned rights. Reference herein to any specific commercial product, process, or service by trade name, trademark, manufacturer, or otherwise, does not necessarily constitute or imply its enforcement, recommendation, or favoring by the United States Government or any agency thereof. The views and opinions of authors expressed herein do not necessarily state or reflect those of the United States Government or any agency thereof.

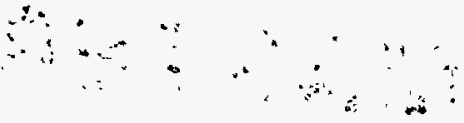




\section{DISCLAIMER}

- Portions of this document may be illegible in electronic image products. Images are produced from the best available original document. 


\section{Options for Monitoring the U.S.-Russian Bilateral Cutoff Agreement On Shutdown of Plutonium Production Reactors}

\section{Executive Summary}

Six options are presented for monitoring operating Russian reactors and reprocessing plants under the bilateral cutoff agreement. In order of increasing intrusiveness they are:

(A) monitoring of product (oxide or metal) storage only, supplemented with transparency measures at the reactors,

(B) monitoring of product storage and reactor operating parameters, to assess reactor plutonium production,

(C) monitoring of product storage, reactor operating parameters, and the input accountability tank of the reprocessing plant,

(D) monitoring of product storage, the input accountability tank of the reprocessing plant, and application of surveillance to spent fuel,

(E) IAEA/NPT-based material accountancy verification without major facility upgrades, and

(F) IAEANNPT-based safeguards, attempting to fulfill IAEA standards for material accountancy accuracy.

Each of these options is considered in terms of cost, inspection effort, and effectiveness; however, the paper emphasizes the many uncertainties attendant on such assessments based on our current state of knowledge of these facilities. The options are assessed as follows:

- Only options $E$ and F conform to the IAEA/NPT "standard" in terms of verification objectives and completeness of material balance verification activities.

- Option $A$ is the weakest of the options in terms of verification, in that there is no independent means (aside from NTM in conjunction with the transparency measures) of assessing the amounts of material that should be coming into monitored storage.

- Option B is significantly lower in cost and intrusiveness than options C - E, but retains at least the potential for providing the assurance referred to in Article II of the bilateral . agreement. It depends, however, on the implementation of a technique which is untried as a verification measure (although the calculations are well established technology); US and Russian experts would have to cooperate in developing the plutonium production calculation and reactor monitoring techniques.

- Option C would add increased accuracy to the methods of Option B, but at the cost. of incrementing the inspection effort from monthly visits to a continuous on-site inspection presence of a small inspection team at each location.

- Option $D$ obviates the need for the development of the reactor plutonium calculations, at the cost of considerably increased inspector presence in the reactors, and the installation of containment and surveillance equipment. While this containment and surveillance technology is well-developed, it is possible that the configuration and operation the Russian reactors is such that some specialized new hardware would have to be developed (as was the case for Candu reactors). 
- Options $E$ and $F$ are the most intrusive, and would involve a large team (perhaps 5 to 10) of inspectors with continuous presence at each site. The major issue associated with these options are whether the Russian plants have the material accounting infrastructure (and other facility characteristics) to support a reasonably accurate verification of the full material balance, particularly the measurement of the in-process inventory. What little we do know of Russian facilities gives little cause for optimism. Upgrades to accomplish this may be expensive, and without the upgrades traditional IAEA methods may not be effective.

This enumeration bounds but does not exhaust the set of possible inspection strategies. Any decisions made about the nature of the inspection regime should await visits to the facilities and indications of the extent of Russian willingness to support the inspection effort. 


\section{Introduction}

This paper provides a framework for assessing verification options for the US-Russian "Cessation Agreement" of June 1994. It deals only with operating Russian production reactors and reprocessing facilities (the non-operating facilities are an easier problem), and does not address the possibility that product plutonium might leave the storage area. Section 2 describes plutonium production and processing in a reactor and reprocessing plant in general terms and in the context of known characteristics of the Russian facilities. Section 3 identifies eight areas for the potential application of monitoring techniques, and eleven potential inspection objectives. These are combined to form a graded set of six monitoring regimes (ranging from minimalist to full NPT-like safeguards) in Section 4. Each regime is assessed in terms of cost, inspection effort, and effectiveness.

This paper should be regarded as an attempt to structure possibilities rather than to predict outcomes or results. The cost, effectiveness, and practical applicability of most of the monitoring techniques discussed depend strongly on details of facility design, process conditions, domestic safeguards infrastructure, and operating schedules of which we have little if any information. These uncertainties are emphasized throughout the paper. It would be foolish to promote specific monitoring approaches until visits are made to the Russian plants and more is known of the extent of Russian support for a bilateral inspection effort.

\section{Facility Descriptions}

The following descriptions are based on unclassified conversations with DOE personnel involved with the reactor shutdown negotiations or the visit to the Tomsk reprocessing plant following the 1993 accident. Figure 1 below illustrates in a general way the flow of plutonium through key points in the production process.

\section{Reactors}

The reactors are assumed to have a thermal power of about 2000 megawatts, and an inventory of about 300 tons of heavy metal, distributed in about 2700 pressure tubes with 70 fuel elements per tube. Each element is about $10 \mathrm{~cm}$ in length and weighs about 1.6 $\mathrm{kg}$. After a month of operation, about half of the core (94,500 fuel elements) is discharged; these elements will contain about $60 \mathrm{~kg}$. of plutonium. The majority of the fuel channels are natural uranium fuel (aluminum clad uranium-metal). 100 channels are used for axial or radial flux shaping. These consist of highly enriched uranium diluted in an aluminum matrix. The slugs are the same size as the natural uranium fuel slugs, although the weight of each slug is much less.

Two weeks are needed for each refueling operation; the reactor is assumed to be shut down during this time. Discharged spent fuel is transported to a spent fuel pool. From there, the spent fuel is transported in some type of shielded cask, probably on a rail car, to the reprocessing plant.

If one assumes continuous shipments occurring on $80 \%$ of 365 days per year, about 2,600 fuel elements would be shipped each day. On the other hand, shipments could occur in a smaller number of larger campaigns; for example, 8 shipment campaigns per year, with 94,500 elements per shipment campaign. 


\section{Reprocessing Plants}

The reprocessing plants use the PUREX solvent extraction method and were built to service several simultaneously operating production reactors. Aside from this information, very little is known about these facilities. Conventionally, spent fuel would be stored temporarily in a storage pool before charging to a nitric acid dissolver. Dissolved spent fuel would go to an input accountability tank for volume measurement and sampling for plutonium content. This is a crucial step both for process control and for plutonium accountability. Thereafter, the solution enters the separation process to split the plutonium and uranium from the fission products. These chemical steps must occur in heavily shielded "canyons" for radiation protection. The product of the separations process is a concentrated plutonium nitrate solution.

The next step is the conversion of the nitrate solution to a solid. It is not known if the conversion process occurs in the same facility as the separations process (Figure 1 assumes that the facilities are distinct). This process will differ depending on whether the product is plutonium oxide or plutonium metal. The solid would finally be stored in containers in small quantities for criticality safety.

Key determinants of the inspection needs for the reprocessing plant and conversion area are the operational schedules. These are unknown; a reasonable assumption based upon the reactor refueling rate and a typical dissolver batch size of 35,000 liters and uranium concentration of about 350 grams per liter is that one such batch accumulates every other day per reactor. About five days would be required to accumulate about $8 \mathrm{~kg}$ of plutonium in nitrate solution (per reactor), which is a typical product batch size.

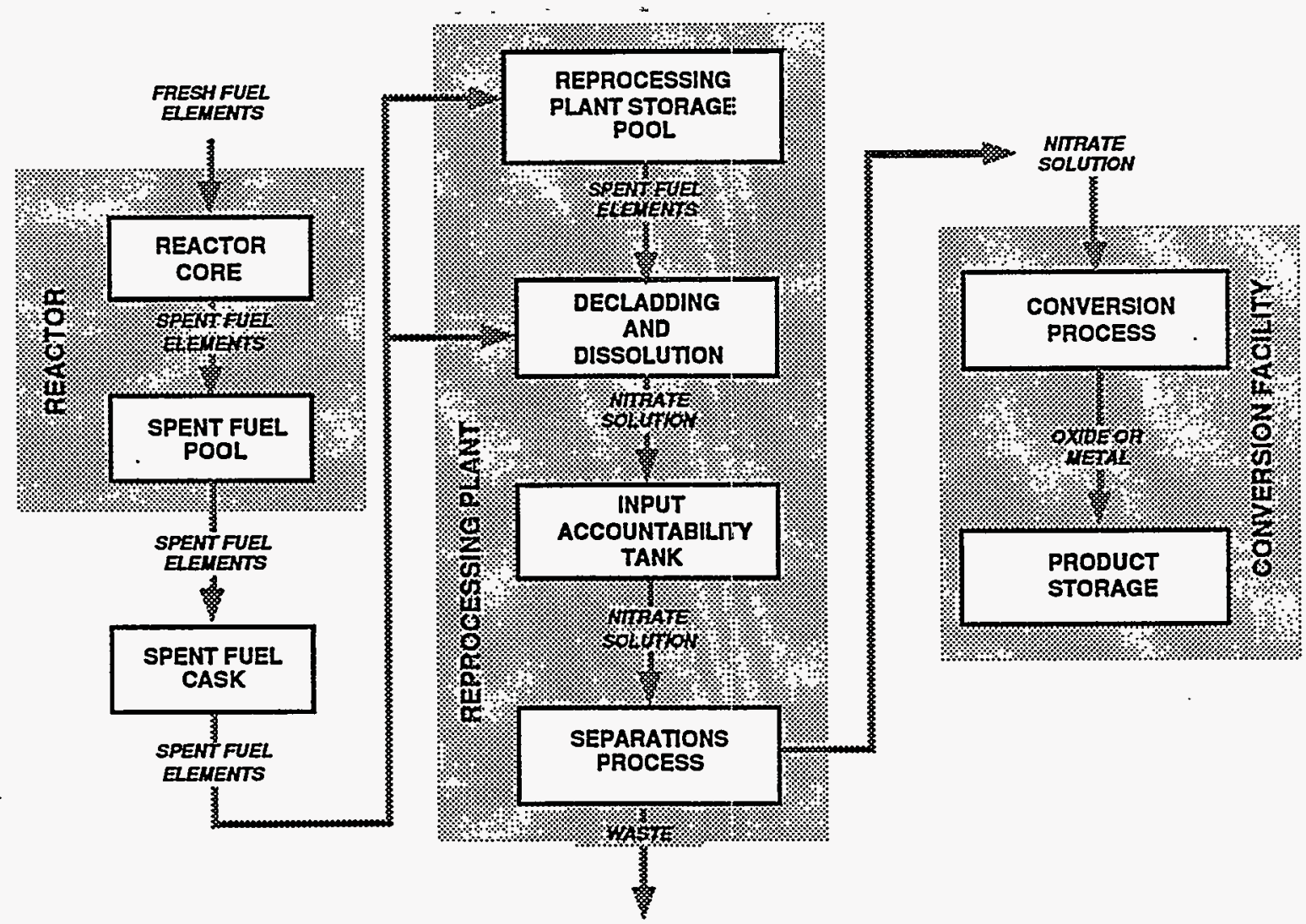

FIGURE 1 


\section{Monitoring Tasks}

This section identifies eight potential areas for the application of monitoring techniques between the creation of plutonium in the reactor and the storage of the plutonium as solid product material. Even in the case of full NPT-like safeguards, not all of these measures are necessary, and there is some logical overlap in some of the objectives and activities. These objectives are summarized in the following table.

\begin{tabular}{|c|c|c|}
\hline Section & Objective & Method \\
\hline 3.1 & Verify plutonium production in reactor & $\begin{array}{l}\text { Monitoring of reactor operational } \\
\text { parameters and computer modeling }\end{array}$ \\
\hline 3.2 (a) & $\begin{array}{l}\text { Verify that all spent fuel discharged from the } \\
\text { reactor goes to the pool, and there are no } \\
\text { undeclared shipments from the pool }\end{array}$ & $\begin{array}{l}\text { Surveillance of pool, and possibly } \\
\text { reactor }\end{array}$ \\
\hline $3.2(b)$ & Verify declared contents of spent fuel pool & $\begin{array}{l}\text { Counting and non-destructive analysis } \\
\text { (NDA) }\end{array}$ \\
\hline 3.3 (a) & $\begin{array}{l}\text { Verify declared contents of shipment from } \\
\text { spent fuel pool }\end{array}$ & $\begin{array}{l}\text { Observation of cask loading, counting } \\
\text { and non-destructive analysis (NDA) }\end{array}$ \\
\hline $3.3(b)$ & $\begin{array}{l}\text { Verify that spent fuel is not diverted between } \\
\text { pool and reprocessing plant }\end{array}$ & Sealing (or observation) \\
\hline $3.4(a)$ & $\begin{array}{l}\text { Verify that spent fuel arriving at réprocessing } \\
\text { plant is dissolved and reaches the input } \\
\text { accountability tank }\end{array}$ & $\begin{array}{l}\text { Surveillance and design verification on } \\
\text { the head -end of the process }\end{array}$ \\
\hline $3.4(b)$ & $\begin{array}{l}\text { Verify the contents of the input accountability } \\
\text { tank }\end{array}$ & $\begin{array}{l}\text { Sampling, analysis, volume } \\
\text { measurement (all observed by } \\
\text { inspector); independent analysis of } \\
\text { sample }\end{array}$ \\
\hline 3.5 & $\begin{array}{l}\text { Verify the inventory of the separations and } \\
\text { conversion process areas }\end{array}$ & $\begin{array}{l}\text { Measurement of in-process materials } \\
\text { including: sampling, analysis, volume } \\
\text { verification, NDA }\end{array}$ \\
\hline 3.6 & Verification of the product & $\begin{array}{l}\text { NDA or analytical chemistry } \\
\text { measurement }\end{array}$ \\
\hline 3.7 & Verification of waste streams & NDA or analytical chemistry \\
\hline 3.8 & Verification of product storage & NDA, seals, possibly surveillance \\
\hline
\end{tabular}

TABLE 1

\subsection{Monitoring of Reactor Plutonium Production}

\section{Objective}

The objective of monitoring reactor plutonium production is to determine the quantity of plutonium produced in the reactor, based on reactor operating parameters. This procedure would rely on detailed reactor design information and selected operating parameters (e.g., reactor power level) and use computer calculations to model reactor 
physics and to estimate plutonium production. The derived information could be used to add confidence to physical measurements of plutonium content (such as measurements of discharged reactor fuel) or could stand alone as an estimate of total plutonium production.

\section{Uncertainties}

The technique would require information on reactor design. Most of the important physical parameters could be fairly easily verified. Calculations of ongoing reactor operations would require, at a minimum, knowledge of reactor power levels. These could be obtained from existing instrumentation (with adequate authentication) or from newly installed instrumentation (channel or main coolant leg flow rates and temperatures). Power level and design information alone should enable plutonium production to be estimated within 5-10\%. Additional precision could be obtained if further operational information were obtained (e.g., control rod positions).

The monitoring of operational parameters to estimate plutonium production is not an established verification technique; some development effort must be anticipated to identify what parameters can be independently monitored, how sensors can be emplaced, and to create the monitoring hardware itself.

\section{Methods}

Reactor physics computer models would be used to estimate plutonium production (estimates would include both total plutonium production as well as the isotopic ratios of the plutonium produced). The use of such models would require fairly detailed design knowledge of the reactor core. Information on fuel design, lattice arrangement, fuel loadings (both natural and the enriched fuel used for axial and radial flux shaping), and control rod operation would be required. Some of this information has already been shared by the Russians; however, some additional details necessary to improve estimates would be needed. Visits and data exchanges with knowledgeable graphite reactor physicists would enhance the value and provide independent verification of the information.

Based on reactor power level and other physical parameters (fuel charges/discharges, control rod worths and positions, core temperature) the detailed operation of the reactors would be modeled. Computer estimates of the plutonium production would be estimated during each operating run. Based on knowledge of parameter uncertainties, parametric studies would be conducted which would provide bounding estimates of plutonium production.

Although readily obtainable reactor operating parameters would provide a plutonium production estimate to within a few percent (easily 5-10\%), additional validation of estimates (e.g., analysis of selected spent fuel slugs) could be used to improve estimation accuracy perhaps to within 1-2\%. Further confidence could be gained by selective measurement of randomly chosen discharged fuel.

\section{Costs}

If no additional instrumentation were required (i.e., only existing instrumentation with authentication would be used) costs should be low. Installation of additional instrumentation in an operating reactor could. be expensive. Estimates are difficult without knowledge of plant layout and access limitations. For example, access to main coolant piping presumably is possible, which would allow installation of flow rate and temperature measuring equipment. The US NRC estimates the cost of a single channel of 
data installed in a commercial reactor at $\$ 50 \mathrm{~K}$. If we assume that 6 data channels are necessary ( 3 temperature and 3 pressure sensors) this amounts to $\$ 300 \mathrm{~K}$.

Since timeliness is not a real issue, secure recording devices could be used, with only periodic visits by non-plant personnel. A two-person team making 4 visits to each rector per year would generate 8 person-days of inspection effort.

Analysis of the reactor data is fairly straightforward. First year model enhancement and validation could be done for $\$ 500 \mathrm{~K}$ with annual calculational and analysis requirements of $\$ 350 \mathrm{~K}$.

\subsection{Verification of the Inventory of the Spent Fuel Pool}

\section{Objective}

The objective of these activities is to verify Russian declaration of the content of the reactor spent fuel pool. This declaration would presumably describe the number of spent fuel elements in the pool and where they were stored. This verification objective could be accomplished in two ways: (a) containment and surveillance could be used to verify that all spent fuel discharged from the reactor remained in the pool (except for that in declared shipments), or (b) counting and measurement techniques could be used to verify the inventory directly. Verification of the pool would be required to meet safeguards criteria incorporating significant quantity and timeliness objectives.

None of the methods described here would actually verify the plutonium content of the spent fuel; 1 it is only possible to verify that what is in the spent fuel pool is actually irradiated fuel. It is not clear whether the spent fuel existing at entry-into-force would be verified.

\section{Unknowns}

At least six months worth (2 - 3 full cores) of discharged fuel must be stored in the pool. It is unknown how the fuel is stored, and how easy it would be to move it or put it into a position in which some sort of measurement could take place. We will assume that it elements are stored in some sort of trays or boxes (perhaps 70 elements, or one channel's worth, to a tray), which would probably have to be stacked one on top of another.

It is also unclear whether fuel coming out of the reactor can be diverted before it arrives at the spent fuel pool. Canadian Candu reactors, which are on-load reactors in which such alternate routes exist, were the subject of a long and expensive verification development effort, aimed at assuring that discharged fuel actually does arrive in the pool. It is possible the Russian reactors exhibit the same characteristics.

\section{Methods}

Standard IAEA practice for the verification of the spent fuel pool at light water reactors involves surveillance, item counting, item identification, and the use of NDA devices such as the Cerenkov detector ${ }^{2}$ (more sophisticated neutron or gamma measuring devices could be used, but would have to be adapted to a new physical configuration). It is unlikely that item identification or the counting of individual elements will be useful in this case.

1 This is not possible to do with any accuracy by non-destructive assay means.

2 This is an image intensifier designed to detect the glowemanating from newly irradiated spent fuel 
Two verification methods are immediately applicable: surveillance of the pool, and inventory verification by tray-counting and NDA. Surveillance cameras can verify that spent fuel has not been removed from the pool, but is not good at verifying movements underwater, or verifying the amount of spent fuel removed in a cask (the next section will treat the problem of verifying shipments). If (as is the case for Candus) the reactor design allows for removal of spent fuel from the core without passage through the spent fuel pool, surveillance of the pool alone obviously will not guarantee that all the material removed from the core is in the pool, and this method would have to be supplemented or abandoned. ${ }^{3}$

A direct verification of spent fuel pool inventory can be used as a stand-alone verification technique, or as a backup to surveillance. This would be useful if surveillance were considered either not adequately effective, or surveillance failed or provided ambiguous results. Verification would involve the counting of whatever units of fuel were visible (stacks of trays, for example) and random selection of trays for NDA measurement to verify that the trays actually contain spent fuel. If the elements are arranged neatly such that each element is visible from the top, Cerenkov viewing would be sufficient to establish that all elements in the tray are irradiated material. ${ }^{4}$ If Cerenkov viewing of all elements in the tray is not possible, neutron or gamma measurements may be possible. If movement of elements is permissible, lifting of some fuel elements for Cerenkov viewing of those beneath would suffice.

\section{Costs}

No facility upgrades are contemplated, and no long-term verification technology development program seems warranted (note however the comment on Candu reactors above).

Surveillance. Costs for surveillance would involve installation of surveillance equipment (about \$40k for the equipment itself) in a spent fuel pool. IAEA inspectors typically review surveillance devices 4 times per year, requiring about 8 person-days of inspection effort. Inspectors must be present when spent fuel is removed from the pool, however (see section 3.3 on verification of transfers).

Inventory by counting and NDA. Six months worth of reactor production (the minimal inventory of the pool) generate about $250 \mathrm{~kg}$. of plutonium; if this might be stored in $1300 \times 4=5200$ trays (of 70 elements each). Using IAEA detection criteria would require sampling rate of $0.4 \%$ of the trays (assuming 70 elements per tray) or $0.0058 \%$ of the elements;5 this yields an IAEA "gross attributes" sample size for NDA (Cerenkov verification) of 20 trays. Once a tray is selected, however, the inspector has to be able to verify (using NDA) that what he is looking at in the tray is spent fuel. This may involve removing some of the elements to see those underneath. As noted above, a major uncertainty is the amount of time it would take to remove a randomly-selected tray to a position suitable for verification.

Depending on how the trays are stacked, movement and NDA of this many trays could take a day to a number of days. If two inspectors are present, one may estimate the

3 It is possible that continuous inspector presence during the refueling operation, along with additional surveillance, might solve this problem.

4 J.D. Chen, "Observations of Cerenkov Glow from Used CANDU Fuel Bundles", Proceedings of the 29th INMM, p.500-506, Las Vegas, 1988

5 Using an $8 \mathrm{~kg}$. detection goal quantity and a $50 \%$ detection probability, and the IAEA "attribute" sample size formula; the sample size does not depend strongly on the size of the tray. 
inspection person-day burden at 2 to 10 per inventory. If this were done as the main means of verification (i.e., surveillance was not considered reliable), and thus repeated four times yearly the person-day burden would be $8-40$ inspection person-days.

\subsection{Verification of spent fuel shipments between reactors and reprocessing plants}

\section{Objectives}

Two objectives are considered: (a) to verify the declaration of the content of the irradiated fuel shipments from the reactor storage pool, and (b) to verify that no irradiated fuel is diverted between removal from the pool and input to the reprocessing plant. Objective (a) is accomplished through observation and NDA techniques in the reactor spent fuel pool; (b) is accomplished by observation and sealing techniques.

It is worth noting that there is some overlap or redundancy in the activities involved with objective (a) with activities described in the previous section (verification of pool inventory) and the next section (verification of the input to the reprocessing plant). If shipped material is placed directly in the dissolver in the reprocessing plant, or if timeliness is not important, some of these activities may be eliminated.

\section{Unknowns}

The specifics of the way. spent fuel is stored, handled, and transported is not known. It is reasonable to assume that spent fuel is transported from the reactor spent fuel pool to the reprocessing plant in large heavily shielded casks on rail cars. It is not known if the reprocessing plant has a storage pool or if the irradiated fuel is taken directly from the cask into the dissolver. If this is the case, then one would expect shipments to occur frequently (perhaps daily) when the reprocessing plant is in operation. On the other hand, if the reprocessing plant had a large storage capacity for spent fuel, shipments could occur less frequently but in larger amounts. For example, 8 shipments per year,just before or after each refueling, with $60 \mathrm{~kg} \mathrm{Pu}$ in about 94,000 elements per shipment, could be all the shipments needed at each reactor.

\section{Methods}

Surveillance devices cannot assess the amount of material moved underwater into a shipping cask; therefore the loading of shipping casks would have to be observed by inspectors. If shipments occur daily, resident or continuous inspection would be needed. The inspectors would count the number of items (trays or elements) as they are loaded into each cask, may sample some items for weighing and NDA (Cerenkov, neutron or gamma measurements), and they would seal the cask before the shipment. The seal would be verified at the reprocessing plant (it is assumed that some sort of sealing procedure can be devised for the cask; alternatively the inspector could actually accompany the cask to the reprocessing plant).

\section{Costs}

If shipments occur only 8 times per year, surveillance of the pool (as described in the previous section) must be used to detect unreported, unscheduled shipments. However, continuous presence of inspectors would no longer be necessary. From a half-core discharge at each refueling, only 6 trays (out of 1350, assuming 70 elements per tray) or 6 elements (out of 94,000) must be verified using Cerenkov viewing or other NDA technique, as described in the previous section. 
Cost estimates are similar to those described in the previous section. If shipments are continuous, continuous inspector presence would be required, and $300 \mathrm{PDI} / \mathrm{yr}$. would be needed. If there are only 8 shipments per year, assuming 20 trays are shipped each day, 6 - 8 PDI would probably be sufficient per shipment, or about 60 PDI per year. Costs for surveillance were considered in the previous section. The cost of seals is minimal.

\subsection{Verification of Reprocessing Plant Input Accountability}

\section{Objectives}

There are again two sub-objectives: (a) verification that material arriving in spent fuel casks actually gets dissolved and sent to the input accountably tank, and (b) verification of the amount of bulk plutonium fed to the separations process from that tank. The input accountability tank, where plutonium nitrate is sent after dissolution of the solid, irradiated fuel elements, is the first location where an accurate measurement of plutonium by destructive analysis is possible. This measured value could therefore confirm reactor plutonium production estimates and provide one element of a'material balance for the reprocessing plant. It can also serve to establish approximately how much product should eventually appear in the product storage vault.

\section{Unknowns}

It is not known how the spent fuel moves to the dissolver: The reprocessing plant may or may not have a storage pool for the temporary storage of spent fuel. This is necessary to know how possible paths for spent fuel diversion can to be covered by surveillance. Some type of design.verification will probably be needed to provide assurance that most of the content of the dissolver will actually reaches the accountability tank. Design verification in a new reprocessing plant takes place as the plant is being built; how this can be done in a facility that has already gone hot remains an open question. Without knowledge of the plant, it is difficult to anticipate all the costs that might be encountered in upgrading input accountability; there may, for example, be problems with the sampling mechanism.

Determination of the constituents of the input dissolver solution, particularly the plutonium concentration, is crucial for the proper operation of the reprocessing plant. Therefore it is reasonable to assume that the plant operator has available and uses appropriate methods for homogeneously sampling and measuring the chemical and isotopic concentrations of the dissolver contents. 6 Thus samples should be available for verification analysis. The determination of the volume of the dissolver solution is the second key variable, and the uncertainty in this measurement has a strong effect on the uncertainty on the amount of plutonium entering the plant. The plant should have a way to measure the liquid height in the accountability tank to establish this volume, but how this is done is not known.

Finally, the operational schedule of the plant and, particularly, the rate of dissolution are unknown; this makes estimation of inspection effort difficult.

\section{Methods}

The transfer of spent fuel to the dissolver must be under surveillance; television is a possible surveillance method. The beginning and completion of the dissolution process for each batch would also have to be under surveillance. As noted above, some way

6 The April 1993 accident at the Tomsk reprocessing plant does raise questions about this assumption. 
would have to be devised to provide assurance that the solution was routed to the input accountability tank.

At the accountability tank, the dissolver solution batches are measured for volume, and a sample drawn for a plutonium concentration measurement. Simple manometers or automated gauges based on pressure measurements yield the liquid volume in the tank, given a calibration curve for the tank. The IAEA would generally require a tank calibration exercise to validate this calibration curve. Obtaining a sample usable for verification requires that the inspector observe the sampling operation itself and the many steps of chemical preparation. Then the sample must undergo independent analysis for chemical and isotopic content of uranium and plutonium. This may require sending the sample off-site.

\section{Effort and Cost}

For a rate of spent fuel input of about 150 metric tones per reactor every six weeks, if a dissolver batch is about 35,000 liters at a concentration of about 350 grams per liter ${ }^{7}$ a batch accumulates every second day per reactor. There would be about 3 to $4 \mathrm{~kg}$ of plutonium in each such dissolver batch. Verification would be necessary for each batch. This would require many hours of watching the spent fuel being charged to the dissolver and many hours of checking on the dissolution, both possibly by a surveillance camera, as well as several hours per batch following the sample preparation, almost certainly by human surveillance, and one hour verifying the volume. Depending upon the frequency of batches and the strictness with which the loading and dissolution procedures are witnessed or automated surveillance record checked, the required time could vary from one to three shifts daily while the plant is in operation and probably require a second inspector for part of the time when more than one procedure requires attention. We estimate this effort at $300-600 \mathrm{PDI} / \mathrm{yr}$.

The most reliable and accurate method for determining plutonium concentration is isotopic dilution mass spectrometry. This method requires a mass spectrometer (at a cost of $\$ 500 \mathrm{~K}$, if one did not already exist on site). There would also be substantial costs for performing sample analysis elsewhere. Surveillance equipment would cost about $\$ 40 \mathrm{k}$. The input accountability tank would need to be recalibrated and possibly upgraded in terms of sampling and sparging.

3.5 Inventory verification at a reprocessing plant and conversion plant

\section{Objective}

The goal of interim inspections and physical inventory inspections in reprocessing plants is to obtain an estimate of the current inventory of the facility for the purpose of meeting the timeliness criteria of detecting the diversion of a goal quantity (for NPT safeguards, such inspections occur monthly, with a goal quantity of $8 \mathrm{~kg}$. of plutonium). The physical inventory verification (PIV) takes place annually and are used to close an accurate material balance. Interim inspection are similar to the PIV, but differ in that the plant is not cleaned out in advance to minimize the in-process inventory. The usual practice is to verify the spent fuel inventory at the plant quarterly and the in-process and product inventories monthly.

7 These are typical values for a large plant. 


\section{Unknowns}

Little is known about Russian reprocessing plants and how they are run. Plants that are subject to stringent international or domestic safeguards requirements must have some capability for the accurate measurement of in-process inventory. This simply may not be true in Russia. Problems that are common in US DOE plants and commercial facilities under IAEA safeguards that make the measurement of in-process inventory difficult include: the formation of solids in process tanks, lack of adequate sampling or sparging capability in tanks, liquid holdup in pipes, the lack of accurate liquid level measuring devices, and solid holdup on the surfaces of glove boxes used to process solids. All these problems may well be worse in Russian plants. Again, it is difficult to anticipate what upgrades may be necessary. The material below uses the US PUREX plant as a model.

\section{Methods}

The work involved in an interim or PIV inspection can be greatly facilitated by careful planning by the inspectors and the facilities staff. This includes minimizing product inventories not under $\mathrm{C} / \mathrm{S}$, minimizing spent fuel inventories, and arranging for in-process solutions to be in tanks that are calibrated for volume measurement and that have their contents in a chemical form that minimizes sampling and analytical errors. For inventory in places that are impossible to measure, such as pulsed columns and evaporators, it is possible to develop facility-specific models that predict the amount of material in these locations as a function of plant operating parameters.

Determination of in-process inventories can be made easier with the use of various types of on-line process control instrumentation. However, this type of accounting (nearreal-time accounting) is best implemented in new facilities. Upgrading the instrumentation in a large, old reprocessing plant would cost tens of millions of dollars (\$20-\$30M in 1987 dollars to upgrade the pneumatic control equipment at PUREX with electronic readouts that could be interfaced with a computer.). A more practical scheme for a old facility is to develop a plan with the facility operators to properly configure the plant during the interim inspections to allow random samples to be taken from key tanks. This may involve having to calibrate these tanks under inspector supervision, and improving the sampling capabilities of process tanks. Volume in the tanks would be measured using an electromanometer, with analysis of the concentration by K-edge densitometry or destructive analysis. Upgrading a Russian plant in this manner may still be very expensive.

The problem of solids holdup in the conversion area can be addressed by frequent cleanouts, or by the installation of in-line NDA equipment. This equipment is expensive, and will not provide very good accuracy because of the unknown geometry of the accumulated material.

Costs

The costs for upgrading the ability of the facility to measure in-process inventory can run into tens of millions of dollars. Effort involved in verifying the in-process and product inventories is in the range of $200-400 \mathrm{PDI} /$ year. A K-edge densitometer costs $\$ 50 \mathrm{~K}$ $\$ 100 \mathrm{~K}$, and an electromanometer system costs $\$ 5$ - 10K. The cost for a system of in-line NDA instrumentation to measure solid holdup in -an extensive system of gloveboxes would be in the range of $\$ 500 \mathrm{~K}$ to $\$ 2 \mathrm{M}$. 
3.6 Verification of Product at a Reprocessing Plant

\section{Objective}

The objective of verification of a reprocessing plant's product is primarily to detect diversion of material. It also provides an indication of how much material should be received at the storage facility. If verification is done at the reprocessing plant it could simplify the verification at the storage facility.

\section{Unknowns}

The products of the reprocessing plant could either be plutonium nitrate solution, plutonium oxide (a powder), or plutonium metal. If the product is plutonium nitrate, it would then be taken to a separate facility for conversion into a solid form for storage. This might require additional safeguards at this facility.

\section{Methods}

Verification of product can in principal be done at two places, either as it is brought from the reprocessing plant or at the storage facility. The choice will be dependent on local operating factors such as the availability of measurement instrumentation and lag storage. The procedures involved in verifying the product include measurement of the quantity of plutonium and placement of appropriate inspectorate seals. Measurement of plutonium quantity would either be by NDA or destructive analysis of the product from samples taken as the product container are loaded. NDA of the nitrate solution would use $\mathrm{K}$-edge densitometry to determine the solution concentration. A volume measurement using on electromanometer would also be necessary. For oxide or metal product the NDA would use a neutron coincidence counter plus a gamma ray spectrometer.

Costs

The effort involved will be dependent on the throughput. For a facility handling one metric ton of $\mathrm{Pu}$ per year the effort would be on the order of $70 \mathrm{PDI} /$ year if verification were done at the reprocessing plant or $10 \mathrm{PDI}$ if done by the receiver. The cost of a $\mathrm{K}$ edge densitometer is $\$ 50 \mathrm{~K}-\$ 100 \mathrm{~K}$. The cost of an electromanometer is about $\$ 5-10 \mathrm{~K}$. The neutron coincidence counter would cost $\$ 100 \mathrm{~K}-\$ 125 \mathrm{~K}$ and a gamma ray spectrometer about $\$ 75 \mathrm{~K}$.

\subsection{Verification of Waste Streams}

\section{Objective}

The principle purpose of waste stream verification is to ensure that the waste streams are not being used to divert plutonium and in particular that the facility is not overstating its declaration of the amount of plutonium in the waste streams.

\section{Unknowns}

As with other aspects of reprocessing plant operations the number and location of waste streams is not known.

\section{Methods}

Inspectors would witness the removal of samples from the various waste stream on a random basis. These samples would then be analyzed for plutonium either by destructive analysis or with a gamma ray spectrometer. 
Costs

The effort involved would be about 50 PDI. A gamma ray spectrometer costs about $\$ 75 \mathrm{~K}$.

\subsection{Verification of Product Storage}

\section{Objective}

The objective is to verify the Russian declaration of the content of the product storage area. To meet IAEA-like verification goals on significant quantity and timeliness there must be an annual physical inventory and monthly interim inspections. The verification activities involved fall into several categories: examination of records and reports; verification of receipts; physical inventory verification; interim inspections.

\section{Unknowns}

The product reaching the storage facility is assumed to be plutonium oxide or metal stored in cans. The efficiency of applying safeguards to such a facility will be highly dependent on the design of the facility and the quality of the current domestic safeguards system. These are presently unknown. It must also be assumed that the product material is stored in a facility that will allow the verification activities that are described below; this is not a given. The modifications necessary to allow measurement of product material could cost millions of dollars.

\section{Methods}

Examination of Records and Reports - This activity would be performed at the time of a physical inventory verification or interim inspection. The ease of this task is dependent on the condition of the records. An efficient computerized accounting system would make this task much easier. However, it is to be expected in Russia that a paper system of questionable quality would be used.

Verification of Receipts - Assuming no transfer of material out of the storage facility, the major effort would be on verifying receipts. The amount of activity at the storage facility would depend on what was done at the reprocessing plant. Receipts measured by the shipper and shipped under inspectorate seal would only require verification of the seal. Material shipped without measurement by the shipper, or not shipped under seal would have to be measured and sealed at the storage facility. The effort involved in either case will be dependent on the throughput.

Interim Inspections - Interim inspections would be performed once per month. The activities in addition to the records check are again dependent on the C/S status. Material not under $\mathrm{C} / \mathrm{S}$ must be counted and remeasured using the measurement equipment described above.

Physical Inventory Verification(PIV) - A PIV is performed once a year. The activities at the PIV are dependent of the containment/surveillance (C/S) status: (a) for items under dual $\mathrm{C} / \mathrm{S}$ (seals plus cameras) the would be no requirements for remeasurement for at least three years; (b) for items under single C/S the requirement is a count of all items and remeasurement of a statistical sample of the items; (c) for items not under $\mathrm{C} / \mathrm{S}$ must be counted and reverified. PDI's for (b) and (c) will be dependent on the number of items in storage and the $\mathrm{C} / \mathrm{S}$ status of each item. Credit; for C/S may only be taken if the $\mathrm{C} / \mathrm{S}$ is judged to be performing acceptably. 


\section{Costs}

As noted above, the expense involved in upgrading a vault to the point where verification measurements can take place could range from zero to many millions of dollars.

Examination of Records and Reports - Installation of a modern computerized system would cost $\$ 500 \mathrm{~K}$ to $\$ 1 \mathrm{M}$. The cost is largely determined by the need to make the system facility specific. The actual effort expended in examining the records might require 6 PDI/year.

Verification of Receipts - For a facility handling one metric ton of $\mathrm{Pu}$ per year and assuming $5 \mathrm{~kg}$ containers the expected measurement time is on the order of $70 \mathrm{PDI} / \mathrm{year}$ if verification were done at the storage facility or $10 \mathrm{PDI}$ if done by the shipper. The measurement equipment used would consist of a neutron coincidence counter ( $\$ 100 \mathrm{~K}$ $\$ 125 \mathrm{~K})$ and a gamma ray spectrometer $(-\$ 75 \mathrm{~K})$. These instruments would probably required in the facility to handle any remeasurement required by the failure of C/S as described below.

Physical Inventory Verification(PIV) - Estimated PDI's are 1/year for dual C/S, 10/year single $\mathrm{C} / \mathrm{S}$, and 100/year if the material is not under C/S. Cameras cost approximately $\$ 20 \mathrm{~K}$ per unit. The number required will depend on the layout of the facility, but at least two would be required. Measurement equipment would be the same as that described under Verification of Receipts.

Interim Inspections - For material under C/S'estimated effort is $12 \mathrm{PDI} /$ year. For material not under C/S the PDI could reach 1000/year.

\subsection{Cost/Effort summary}

Table 2 summarizes the costs and inspection effort estimates for the various inspection tasks considered above. The numbers quoted in the first column are in general highly speculative; they depend on what already exists at a facility and how much improvement is considered necessary or worthwhile.

\section{Verification Options}

Six combinations of the verification objectives and activities described in section 3 are considered here. These are summarized in Table 3.

4.1 Option (A): Product verification, supplemented with transparency measures at reactors

\section{Activities}

Formal verification activities would consist of those described in section 3.8 only: inspectors would make monthly visits to the product storage area to measure and seal product containers, and attend to surveillance equipment. Transparency measures at the reactors by the Russians, including declarations of power and plutonium production, would allow comparisons of the amount of material entering the product area with the plutonium declared as having been generated and reprocessed. 


\begin{tabular}{|c|c|c|c|}
\hline & $\begin{array}{l}\text { Facility Upgrades and Initial } \\
\text { Inspection Requirements }\end{array}$ & $\begin{array}{c}\text { Monitoring/Inspection } \\
\text { Instrumentation }\end{array}$ & $\begin{array}{l}\text { Ongoing inspection effort: } \\
\text { PDI/yr/facility }\end{array}$ \\
\hline 3.1 & & $\begin{array}{l}\text { - Reactor operation } \\
\text { monitoring instruments } \\
\text { (e.g., flow/temperature } \\
\text { sensors) } \$ 300 \mathrm{~K} \\
\text { - Plutonium production } \\
\text { modeling: } \$ 500 \mathrm{~K}\end{array}$ & $\begin{array}{l}\text { - Plutonium production } \\
\text { calculations: } \$ 350 \mathrm{~K} / \mathrm{yr} \text {. } \\
\text { - Visits to monitor sensors: } \\
8 \text { PDl/yr.facility }\end{array}$ \\
\hline $3.2(a)$ & & - Surveillance $\$ 40 \mathrm{~K}$ & $\begin{array}{l}\text { - Review surveillance } 5 \text { - } \\
10\end{array}$ \\
\hline 3.2 (b) & & $\begin{array}{l}\text { - Cerenkov image intensifier } \\
\$ 5 \mathrm{~K}\end{array}$ & $\begin{array}{l}\text { - } 8 \text { - } 40 \text { man-days if used } \\
\text { without surveillance }\end{array}$ \\
\hline $3.3(a)$ & & $\begin{array}{l}\text { - Cerenkov image intensifier } \\
\$ 5 \mathrm{~K}\end{array}$ & $\begin{array}{l}\text { - cask loading verification: } \\
100-300\end{array}$ \\
\hline 3.3 (b) & & $\begin{array}{l}\text { - Sealing devices (cost } \\
\text { probably rninimal) }\end{array}$ & - Effort included in $3.3 a$ \\
\hline 3.4 (a) & $\begin{array}{l}\text { Design verification of piping, } \\
\text { configuration of head-end of } \\
\text { plant }\end{array}$ & - Surveillance: $\$ 40 \mathrm{~K}$ & $\begin{array}{l}\text { - Cask unloading } \\
\text { operations: } 50\end{array}$ \\
\hline 3.4 (b) & $\begin{array}{l}\text { Calibration }(\$ 30 \mathrm{~K}) \text { and } \\
\text { upgrade }(\$ 100-500 \mathrm{~K}) \text { of } \\
\text { input accountability tank } \\
\text { - Upgrade of measurements } \\
\text { and measurement control } \\
\text { program (e.g., mass } \\
\text { spectrometer: } \$ 500 \mathrm{~K})\end{array}$ & & $\begin{array}{l}\text { - Input verification: } 300 \text { - } \\
600\end{array}$ \\
\hline 3.5 & $\begin{array}{l}\text { - Upgrades of interior process } \\
\text { tanks and associated } \\
\text { measurement systems; } \\
\text { development of operational } \\
\text { procedures for inventory- } \\
\text { tanking }(\$ ?) \\
\text { - Process monitoring system } \\
(\$ 20-30 \mathrm{M}) \\
\text { - Automation of material } \\
\text { accountability system } \\
(\$ 500 \mathrm{~K}-1 \mathrm{M})\end{array}$ & $\begin{array}{l}\text { - NDA instrumentation: } \$ 75 \mathrm{~K} \\
\text { - In-line NDA holdup } \\
\text { measurement at conversion } \\
\text { facility: } \$ 500 \mathrm{~K}-2 \mathrm{M}\end{array}$ & $\begin{array}{l}\text { - } 11 \text { interim and one PIV at } \\
\text { separations and } \\
\text { conversion plant: } 300\end{array}$ \\
\hline 3.6 & & $\begin{array}{l}\text { - NDA instrumentation: } \$ 200 \text { - } \\
300 \mathrm{~K} \\
\text {. }\end{array}$ & $\begin{array}{l}\text { - Flow verification of } \\
\text { nitrate product: } 200 \\
\text { (assuming distinct } \\
\text { reprocessing \& } \\
\text { conversion facilities) }\end{array}$ \\
\hline 3.7 & & - NDA instrumentation: $\$ 75 \mathrm{~K}$ & $\begin{array}{l}\text { - Measure waste streams: } \\
50\end{array}$ \\
\hline 3.8 & $\begin{array}{l}\text { Upgrade of product vault to } \\
\text { allow inspection activities: } \\
\$ 0-\$ 10 M\end{array}$ & $\begin{array}{l}\text { - Surveillance: } \$ 40 \mathrm{~K} \\
\text { - NDA : } \$ 2.00-300 \mathrm{~K}\end{array}$ & - Monthly inventories: 70 \\
\hline
\end{tabular}

TABLE 2 . 


\begin{tabular}{|c|c|c|}
\hline Option & $\begin{array}{l}\text { Objectives } \\
\text { (from Table 1) }\end{array}$ & Comments \\
\hline A & 3.8 & Product storage monitoring only: least credible verification regime \\
\hline B & $3.1,3.8$ & $\begin{array}{l}\text { Adds methods for estimating and monitoring reactor plutonium } \\
\text { production; these would have to be developed and agreed upon. }\end{array}$ \\
\hline C & $3.1,3.4$ (b), 3.8 & $\begin{array}{l}\text { Product storage, reactor Pu production, plus verification of } \\
\text { reprocessing plant input; considerable increase in effort, but would } \\
\text { provide additional accuracy }\end{array}$ \\
\hline$D$ & $\begin{array}{l}3.2(a), 3.3(b) \\
3.4(a, b), 3.8\end{array}$ & $\begin{array}{l}\text { Uses containment/surveillance of spent fuel in place of reactor } \\
\text { plutonium calculations. }\end{array}$ \\
\hline $\mathbf{E}$ & all except 3.1 & $\begin{array}{l}\text { Based on NPT-like verification methods, but without extensive } \\
\text { facility upgrades }\end{array}$ \\
\hline $\mathbf{F}$ & all except 3.1 & $\begin{array}{l}\text { Based on NPT-like verification methods, attempts to satisfy current } \\
\text { IAEA safeguards criteria }\end{array}$ \\
\hline
\end{tabular}

\section{TABLE 3}

\section{Effectiveness}

The level of assurance provided by this option would depend on the extent of the transparency measures undertaken to demonstrate the operating parameters of the reactor, perhaps combined with independent information gained from NTM. Transparency measures could be supplemented. with unannounced visits to the reactor. The uncertainty surrounding the amount of plutonium generated by the reactors would still probably be much larger than that for the other schemes.

Costs

- Facility upgrade costs: $\$ 0-10 \mathrm{M}$ to upgrade the storage facility to a point where measurement activities. can occur.

- Ongoing costs: about $70 \mathrm{PDI} / \mathrm{yr}$. (person-days of inspection effort per year) ${ }^{8}$ for monthly visits to verify receipts. Continuous inspection presence not required

- Safeguards equipment: Surveillance devices for the product storage area would cost about $\$ 40 \mathrm{~K}$, and NDA equipment $\$ 200$ - 300K.

4.2 Option (B): Verification of reactor plutonium production and product storage

\section{Activities}

The activities are those described in sections 3.1 and 3.8. Inspectors would have some means of monitoring the power production and plutonium production in the reactors. In addition, inspectors would make monthly visits to the product storage area to measure and seal product containers, and attend to surveillance equipment. The cumulative amount of material placed under verification as product would be compared to the

\footnotetext{
8 This is a unit used by the IAEA as a measure of inspection effort. One PDI is accrued if an inspector spends a day (or any part of a day) on-site in inspection activities. Travel time is not included
} 
amount derived from reactor production calculations. Gamma spectroscopy measurements on the plutonium product would be necessary to provide assurance that no advantage was being gained through the substitution of impure plutonium or plutonium with less favorable isotopics.

Effectiveness

The effectiveness of this option depends on the agreed accuracy of the reactor production calculations and the possible willingness of the Russians to put extra material under verification. It is plausible, for example, we can agree on a common method of estimating the plutonium production of the reactors that is accurate to, say, $X \%$, and that the Russians would agree to place $100+X \%$ of the estimated plutonium production under verification as soon as it is discharged from the reactor. This would eliminate any real possibility of the Russians making use of the reactors as a source of plutonium for weapons. If the Russians will only agree to a $100 \%$ value, there is the (technical) possibility that the Russians could divert approximately $X \%$ of the plutonium and conceal it in this measurement uncertainty.

Even in the best of cases, this option does not conform to NPT safeguards practice, and will not detect "diversion" in the sense of INFCIRC/153. It would, however, force the Russians to substitute equivalent material for any diverted material, and could in fact result in more material being placed in safeguarded storage than is produced.

It should be noted that there may be uncertainties on the order of a few percent even if the reprocessing plant input accountability value is used to estimate the amount of plutonium in the spent fuel.

Costs

- Facility upgrade costs: $\$ 0-\$ 10 \mathrm{M}$ to upgrade the product storage facility to a point where measurement activities can occur.

- Ongoing costs:

$70 \mathrm{PDI} / \mathrm{yr}$. for monthly visits to verify product receipts. Continuos inspection presence not required.

Visits to reactor to verify operation could occur at the same time, adding only a few extra days of inspection effort.

- Safeguards equipment: Surveillance devices for the product storage area would cost about $\$ 40 \mathrm{~K}$, and NDA equipment $\$ 200$ - 300K.

- Development, purchase and installation of reactor monitoring equipment: $\$ 300 \mathrm{~K}$; $\$ 500 \mathrm{~K}$ for initial reactor modelling and $\$ 350 \mathrm{~K} / \mathrm{yr}$. for calculations.

\section{Comments}

The method of calculating reactor plutonium production would have to be agreed upon by a panel of experts from both states. Methods for monitoring reactor operation would have to be developed. 
4.3 Option (C): Production, input accountability, and product storage verification

\section{Activities}

The activities are those described in sections 3.1, 3.4 (objective b), and 3.8. Inspectors would have some means of monitoring the power production and plutonium production in the reactors. They would verify the input to the reprocessing plant by (inter alia) observing the volume of liquid in the input accountability tank and by obtaining samples from the tank. In addition, inspectors would make monthly visits to the product storage area to measure and seal product containers, and attend to surveillance equipment.

The cumulative amount of plutonium placed under verification as product would be compared to the verified amount input to the reprocessing plant. Input accountability values for both plutonium and uranium could be compared to declared values, and those values would have to be consistent with reactor operations and the production calculations.

Gamma spectroscopy measurements on the plutonium product would be necessary to provide assurance that no advantage was being gained through the substitution of impure plutonium or plutonium with less favorable isotopics.

\section{Effectiveness}

The value for plutonium derived from sampling and analysis at the input accountability tank is probably more accurate than that derivable from reactor calculations, so that diversion of material from the reprocessing or conversion facility would be more constrained. The information from the concentrations of uranium and plutonium and the plutonium isotopics that come from the accountability tank sample will probably also improve the overall accuracy of the plutonium accounting.

Again, this option does not conform to NPT safeguards practice, because the inventories of the facilities are not verified, implying that timeliness criteria could not be achieved.

An unresolved issue for this option is the amount of plutonium in the waste streams; presumably the Russians could overstate the amount of plutonium in waste streams and divert that amount (which should, however, be small).

As in option 2, any drawbacks associated with uncertainties inherent in the material accounting scheme could be negated if the Russians agreed to place slightly more material under verification in a timely manner.

Costs / Effort

- Facility upgrade costs: $\$ 0-\$ 10 \mathrm{M}$ to upgrade the storage facility to a point where measurement activities can occur.

- Upgrade of the input accountability measurements, measurement control system, etc. Perhaps $\$ 100$ - 500K.

- Ongoing costs: $300-600 \mathrm{PDI} / \mathrm{yr}$. to verify input accountability; $70 \mathrm{PDI} / \mathrm{yr}$. for monthly visits to verify product receipts; a few per year visits to each reactor to verify operation of reactor and reactor monitoring devices. This might be accomplished with the continuous presence of 2 to 3 inspectors.

- Safeguards equipment: Surveillance devices for the product storage area would cost about $\$ 40 \mathrm{~K}$, and NDA equipment $\$ 200$ - 300K. 
- Development, purchase and installation of reactor monitoring equipment: $\$ 300 \mathrm{~K}$; $\$ 500 \mathrm{~K}$ for initial reactor modelling and $\$ 350 \mathrm{~K} / \mathrm{yr}$. for calculations.

\section{Comments}

The method of calculating reactor plutonium production would have to be agreed upon by a panel of experts from both states. Methods for monitoring reactor operation would have to be developed.

\subsection{Option (D): Spent fuel, input accountability, and product storage verification}

\section{Activities}

The activities are those described in sections 3.2 (objective a), 3.3 (objective b) , 3.4, and 3.8. Inspectors would verify that all the spent fuel discharged from the reactor goes to the spent fuel pool, and that all spent fuel removed from the pool goes to the reprocessing plant. They would verify the input to the reprocessing plant and would make monthly visits to the product storage area to measure and seal product containers, and attend to surveillance equipment.

The verified amount of plutonium that was input to the accountability tank would be compared to the material verified as product. Gamma spectroscopy measurements on the plutonium product would also be necessary to provide assurance that no advantage was being gained through the substitution of impure plutonium or plutonium with less favorable isotopics.

\section{Effectiveness}

The difference between this option and option $\mathrm{C}$ is that surveillance is substituted for the reactor plutonium production calculation. If this surveillance is effective, ${ }^{9}$ it provides assurance that all the plutonium coming out of the reactor gets accounted for in the reprocessing plant accountability tank. In this case the uncertainty associated with the reactor plutonium calculation is eliminated, along with the possibility of diversion between the reactor and the reprocessing plant. The only remaining possibility is to divert from the reprocessing plant an amount of material on the same order as the measurement uncertainty for the accountability tank.

Again, this option does not conform to INPT safeguards practice, because the inventories of the facilities are not verified.

\section{Costs / Effort}

- Facility upgrade costs: $\$ 0-10 \mathrm{M}$ to upgrade the storage facility to a point where measurement activities can occur.

- Upgrade of the input accountability measurements, measurement control system, etc. Perhaps $\$ 100-500 \mathrm{~K}$.

- Verification of design information on head-end

- Ongoing costs: 300 - $600 \mathrm{PDI} / \mathrm{yr}$. to verify input accountability; $70 \mathrm{PDI} / \mathrm{yr}$. for monthly visits to verify product receipts; $60-300 \mathrm{PDI} / \mathrm{yr}$./reactor for verification of

9 Under the circumstances usually faced by the IAEA (for example a light water reactor shipping to a commercial reprocessing plant whose design information has been verified) this can be done effectively. Without detailed knowledge of the configuration of the reactor and the reprocessing tank head end, it is not possible to say what type of effort would be required to have confidence in this case. 
loading of spent fuel casks. This amounts to the continuous presence of 3 to 5 persons.

- Safeguards equipment: Surveillance devices for the product storage area would cost about $\$ 40 \mathrm{~K}$, and NDA equipment $\$ 200$ - 300K.

4.5 Option (E): NPT-based verification without major facility modifications

\section{Activities}

Under safeguards as applied under INFCIRC/153, the material balance of each facility under safeguards would have to be verified. This would include activities $3.2 \mathrm{a}, 3.3 \mathrm{a}, 3.3 \mathrm{~b}$, 3.4a, 3.4b, 3.5, 3.6 (provided the conversion facility was separate), 3.7 and 3.8 of Table 1. Re-verification of the spent fuel pool using activity $3.2 \mathrm{~b}$ would be required in certain cases of failure or ambiguity of surveillance. All the flows between facilities would be monitored either by sealing and surveillance techniques or by measurements. Inventory inspections would occur monthly in the reprocessing and conversion facilities, and a physical inventory verification would occur at the end of the year.

The activities identified in this option do not differ substantively from those in the next option; what differentiates the two is the extent of facility upgrades (column two in Table 3). This option assumes that neither side is willing to pay for extensive upgrading of reprocessing and conversion plant material accounting capability.

\section{Effectiveness}

Under NPT safeguards, the objective is to detect diversion in a timely manner though verification of the entire material balance, including facility inventories. Options $A-D$ did not seek to verify the in-process inventory of the reprocessing or conversion plants (in effect, considering this material "grandfathered"). Thus only options E and F attempt to "detect diversion" (in the sense that this phrase is generally used) and to satisfy timeliness criteria.

The IAEA safeguards goals of the detection of diversion of one significant quantity (8 kg. of plutonium) in a timely (one-month) manner are not achievable in a large commercial reprocessing plant, even with the benefit of a modern accounting infrastructure. It is anticipated that accurately closing the material balance at a Russian reprocessing or conversion facility will be very difficult without extensive upgrades, which are not part of this option. The main problem is likely to be in-process material which cannot be measured or verified. Poor measurement control and unmeasured sidestreams may also cause problems. How much of this material there is cannot be known without detailed knowledge of the operation of the facilities. In the worst of cases, there would be so much unmeasurable material that the traditional IAEA accounting statistic (the MUF or "material unaccounted for") would not be a useful indicator. The problem could be partially addressed if the facility operator is willing to shift material to locations where it can be more easily measured, but this will have a real impact on operations.

Costs

- Some investment in the facility accounting system will probably be necessary even in a "come-as-you-are" scenario. These include upgrades necessary to make the product storage areas inspection-friendly and some calibration to the input accountability tank 
- The inspection burden for one or two reactors and a reprocessing plant should be 1000 - 2000 PDI. This would require an on-site presence of a team of $4-8$ persons.

- Safeguards equipment: Surveillance devices for the product storage area would cost about $\$ 40 \mathrm{~K}$, and NDA equipment $\$ 200$ - 300K.

\subsection{Option (F): NPT-based verification attempting to fulfill IAEA criteria}

\section{Activities}

The inspection activities in this option would be the same as those in Option E.

\section{Effectiveness}

The effectiveness of the option would be determined by the uncertainty in the material balance for the reprocessing plant and the conversion area. With a modern material accounting infrastructure, a large reprocessing plant may come close to achieving or even may even achieve an 8-kilogram detection capability for an abrupt diversion (i.e., where 8 kilograms is diverted in one month). However, the uncertainty on the material balance of the reprocessing plant is unlikely to be much less than about $1 \%, 10$ and for plants expected to have a throughput of $700-1400 \mathrm{~kg}$. of plutonium, this implies a detection capability of about $20-40 \mathrm{~kg}$. if the diversion occurred over the course of a year. ${ }^{11}$

Costs

The costs of bringing a Russian reprocessing plant up to modern material accounting standards could easily run to tens of millions of dollars. It also would take many years. The inspection effort would be similar to that of the previous option (1000 - 2000 PDI/yr.) and the required instrumentation similar.

\section{Cost Summary}

The following table and graphs summarize the instrumentation costs and yearly operational costs identified for the six options, in millions of dollars. Three reactors and two reprocessing plants are assumed; no account is taken of possible conservation of effort due to co-location of facilities. A man-day of inspection effort is assessed at $\$ 5000$. The two shades of gray on the graph (when they occur) represent a range of costs. The table and graphs are derivable directly from tables 2 and 3.

10 The IAEA has specified $1 \%$ as the "expected accuracy" for closing a material balance at a reprocessing plant. In this sense, a plant achieving this level of accuracy/ meets IAEA standards of material accounting performance, even if the $8 \mathrm{Kg}$. goal is not achieved.

11 "Detection sensitivity" at high dectection probability and low false alarm rate is $3-4$ times the (onesigma) uncertainty inthe material balance. 


\begin{tabular}{|ccc|}
\hline Option & Yearly Cost: $\$ M$ & Instrumentation: $\$ M$ \\
A & 0.7 & $0.5-0.7$ \\
B & 1.2 & $2.0-2.2$ \\
C & $4.3-7.2$ & $2.0-2.2$ \\
D & $4.5-8.7$ & $0.7-0.9$ \\
E & $7-12$ & $1.2-6.0$ \\
F & $7-12$ & $1.2-6.0$ \\
\hline
\end{tabular}

TABLE 4
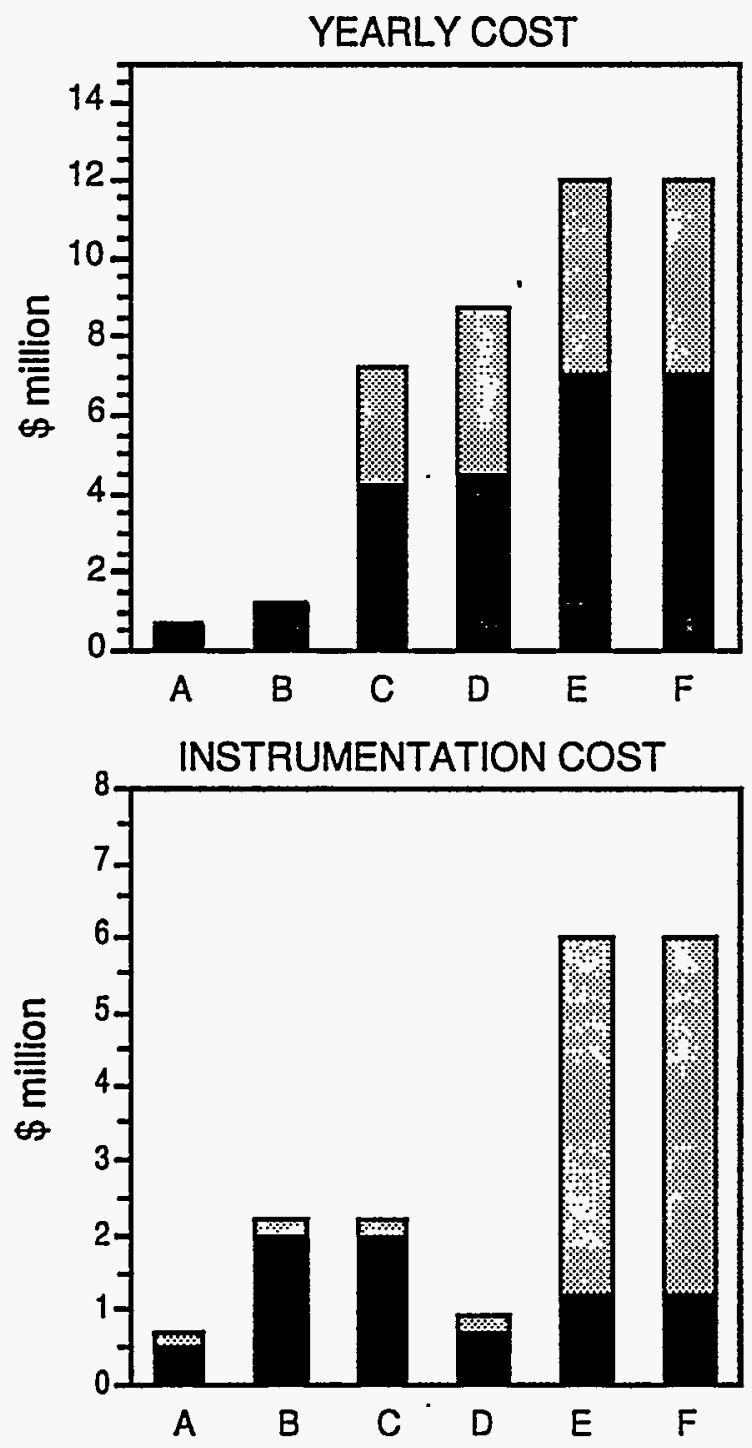